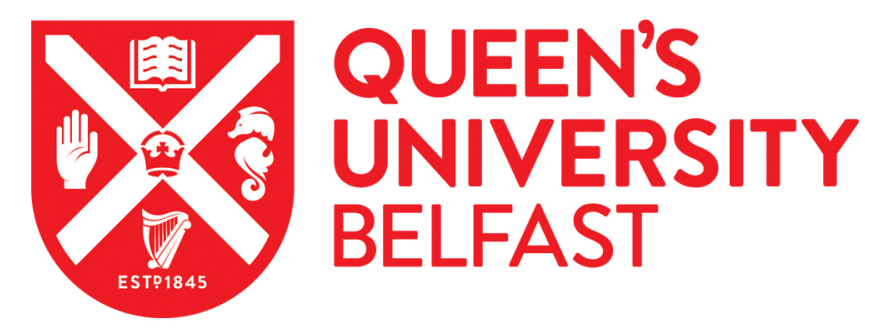

\title{
Cold atmospheric pressure plasma jets as sources of singlet delta oxygen for biomedical applications
}

Sousa, J. S., Niemi, K., Cox, L. J., Algwari, Q. T., Gans, T., \& O'Connell, D. (2011). Cold atmospheric pressure plasma jets as sources of singlet delta oxygen for biomedical applications. Journal of Applied Physics, 109(12), [123302]. https://doi.org/10.1063/1.3601347

Published in:

Journal of Applied Physics

Document Version:

Publisher's PDF, also known as Version of record

Queen's University Belfast - Research Portal:

Link to publication record in Queen's University Belfast Research Portal

Publisher rights

Copyright 2011 American Institute of Physics.

This work is made available online in accordance with the publisher's policies. Please refer to any applicable terms of use of the publisher.

\section{General rights}

Copyright for the publications made accessible via the Queen's University Belfast Research Portal is retained by the author(s) and / or other copyright owners and it is a condition of accessing these publications that users recognise and abide by the legal requirements associated with these rights.

Take down policy

The Research Portal is Queen's institutional repository that provides access to Queen's research output. Every effort has been made to ensure that content in the Research Portal does not infringe any person's rights, or applicable UK laws. If you discover content in the Research Portal that you believe breaches copyright or violates any law, please contact openaccess@qub.ac.uk. 


\title{
Cold atmospheric pressure plasma jets as sources of singlet delta oxygen for biomedical applications
}

\author{
J. S. Sousa, ${ }^{a)}$ K. Niemi, L. J. Cox, Q. Th. Algwari, T. Gans, and D. O'Connell \\ Centre for Plasma Physics, School of Mathematics and Physics, Queen's University Belfast, \\ University Road, Belfast BT7 INN, Northern Ireland, United Kingdom
}

(Received 11 March 2011; accepted 14 May 2011; published online 23 June 2011)

\begin{abstract}
Absolute densities of singlet delta oxygen (SDO) molecules were measured using infrared optical emission spectroscopy in the flowing effluents of two different atmospheric-pressure plasma jets (APPJs): a capacitively coupled radio-frequency-driven jet (rf-APPJ) and a lower frequency kilohertz-driven dielectric barrier discharge jet. The plasma jets were operated in helium, with small admixtures of molecular oxygen $\left(\mathrm{O}_{2}<2 \%\right)$. High absolute SDO densities of up to $6.2 \times 10^{15}$ $\mathrm{cm}^{-3}$ were measured at approximately $10 \mathrm{~cm}$ downstream. The rf-APPJ seems to be much more efficient in producing SDO. The influence of different parameters, such as gas flows and mixtures and power coupled to the plasmas, on the production of SDO by the two APPJs has been investigated. Despite the considerable differences between the two plasma jets (excitation frequency, electric field direction, inter-electrode distance, plasma propagation), similar dependencies on the oxygen admixture and on the dissipated power were found in both APPJs. However, opposite trends were observed for the gas flow dependence. The results presented in this paper show that the control of the external operating conditions of each APPJ enables the tailoring of the SDO composition of both plasma effluents. This provides scope to tune the plasma jets for desired applications, e.g., in biomedicine. (c) 2011 American Institute of Physics. [doi:10.1063/1.3601347]
\end{abstract}

\section{INTRODUCTION}

Over the past years, there has been a rapidly growing interest in the development of non-thermal plasma sources and their characterization for integration in new therapeutic strategies. ${ }^{1-4}$ A new field of biomedical applications of plasmas is emerging as an interdisciplinary research topic of increasing importance, exploring considerable opportunities at the interface of plasma physics, chemistry, and engineering with the life sciences. Research studies in this new research field, now known as plasma medicine, include work on the interaction of plasma with living cells, tissues, and organs and have potential applications in wound healing and tissue regeneration, blood coagulation, sterilization and decontamination, dentistry, and plasma-mediated cancer therapy, among others. ${ }^{5-9}$ Plasma technologies for biomedical applications are in their infancy but offer huge potential payoffs for society. The stable operation of atmospheric pressure plasmas suppressing thermal instabilities is requisite, as is the strict control of the gas temperature for the treatment of temperature-sensitive materials and living tissues. This is possible through high gas flows and by utilizing gases with high heat conductivities, such as helium. Techniques for delaying or preventing the onset of discharge instabilities include external circuit control (short excitation pulses), ${ }^{10}$ dielectric barriers (essentially blocking capacitors), ${ }^{11}$ and confinement of the plasma to small geometries, ${ }^{12}$ from a few micrometers

\footnotetext{
a) Author to whom correspondence should be addressed. Electronic mail: s.sousa@qub.ac.uk.
}

up to a few millimeters. These discharges, often referred to as microplasmas, can be characterized by dimensions of less than $1 \mathrm{~mm}$ and gas pressures of up to atmospheric. Through additions of molecular gas mixtures, a dry reactive chemistry can be created at atmospheric pressure and room temperature. This unique environment offers a large potential application base.

Atmospheric pressure plasma jets (APPJs) offer the possibility of delivering in open air, at ambient pressure and temperature, a unique reactive dry chemistry (radicals, UV radiation, and in some cases even positive and/or negative ions and electrons) to a target located some centimeters away from the main discharge zone. This property opens up a host of new and interesting possibilities including, among others, extremely localized treatments (down to the dimensions of living cells), 2D and 3D treatments (cleaning and thin film deposition), nanomaterial production, decontamination, and biomedical applications. The possibility of producing non-thermal APPJs was recognized in the 1990s by Koinuma et al. ${ }^{13}$ Under certain operating conditions, a jet exits from the axis of the main discharge chamber. The jet appears as a thin, stable plasma column, extending up to a few centimeters from the main discharge into ambient, atmospheric pressure air. The critical confining structures of APPJs vary between some millimeters down to micron scales; hence they are often referred to as microplasma jets, or simply microjets. Depending on the specific geometry and electrical excitation scheme used, microplasma jets can have very different properties. ${ }^{14-21}$ 


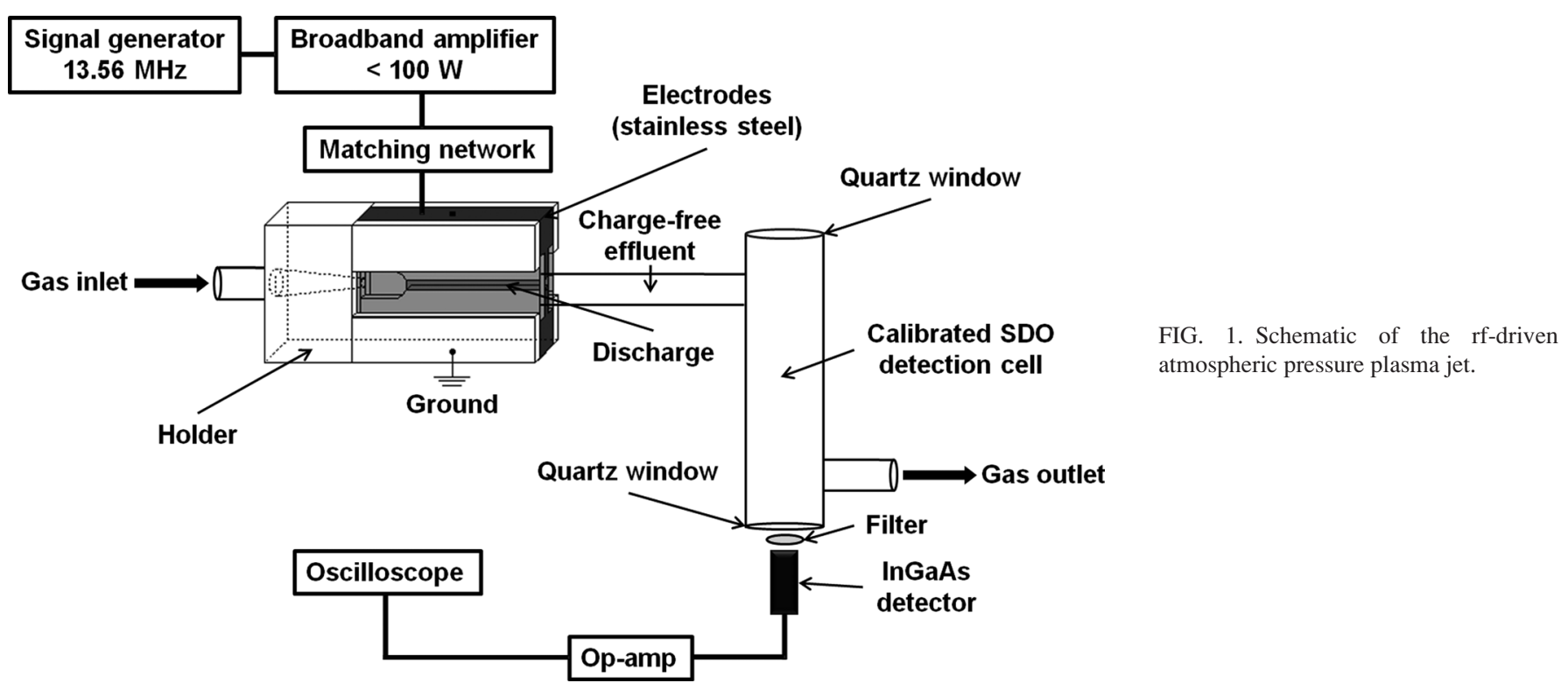

Despite their enormous potential for technological applications, the fundamentals of APPJs are only poorly understood. An understanding of the fundamental plasma chemistry is vital for the development and optimization of such plasma sources. The quantitative measurement of individual particle densities and fluxes provides important information. When operated in helium with a small oxygen admixture, APPJs can efficiently produce high densities $\left(\sim 10^{15} \mathrm{~cm}^{-3}\right)$ of reactive oxygen species (ROS) in the gas phase at low gas temperatures, ${ }^{22,23}$ which is essential for sensitive surface treatments in bio-medicine. ${ }^{24-26}$ These ROS can be carried with the plasma plume onto the surface of solid or liquid samples, e.g., a liquid buffer solution containing bio-material, namely, bacteria or DNA material. ${ }^{27}$ One of the most important ROS is believed to be singlet delta oxygen $\left(\mathrm{SDO}, \mathrm{O}_{2}^{*}\right.$ ), which is well known as an important agent in numerous biophysical and biochemical processes, and which plays a major role in several biological systems. ${ }^{28-30}$ Indeed, SDO not only generates oxidative damage in a variety of biological targets, ${ }^{26,31-33}$ but also is a primary active species in the killing of tumor cells in the emerging cancer therapy known as photodynamic therapy. ${ }^{34-37}$ SDO's most remarkable feature is its extremely long and unique radiative lifetime of more than 75 min in gas phase. ${ }^{29}$ Having an excitation energy of $0.98 \mathrm{eV}$, SDO is a highly reactive chemical molecule. As such, SDO plays an important role in gas and liquid chemistry, and has therefore attracted the attention of many scientists working in virtually every field of the natural sciences, from physics to medicine, through chemistry and biology.

In this paper, in view of APPJs' potential biomedical applications, two different plasma sources have been studied: a radio-frequency-driven jet (rf-APPJ) and a lower frequency kilohertz-driven jet ( $\mathrm{kHz}$-APPJ). Special attention has been devoted to the plasma's effluents. The results of absolute SDO density measurements obtained via infrared optical emission spectroscopy in those regions are presented and interpreted.

\section{EXPERIMENTAL SETUP}

\section{A. Plasma sources: APPJs}

Two different APPJs have been used in our studies: a capacitively coupled radio-frequency-driven jet and a lower frequency kilohertz-driven dielectric barrier discharge jet. Both jets produce non-thermal atmospheric pressure plasmas. The plasma jets have been operated with $\mathrm{He} / \mathrm{O}_{2}$ mixtures $\left(\mathrm{O}_{2}<2 \%\right)$, and the plasma effluent is emitted into ambient air. Helium is used as the main carrier gas in both plasma jets. The total gas flow can be varied in a similar range (up to 10 liters per minute at standard temperature and pressure $[\mathrm{slm}]$ ) in both APPJs, resulting in very different gas velocities. For typical operational flows $(1 \mathrm{slm}$ for the rfAPPJ, and $2 \mathrm{slm}$ for the $\mathrm{kHz}$-APPJ), the gas velocity in the two APPJ devices differs by almost one order of magnitude (see Figs. 6(a) and 6(b) in Sec. III). The gas flow in both jets is laminar (Reynolds numbers of few hundreds) throughout the operational range.

The setup of the investigated rf-APPJ is shown in Fig. 1. It consists of two planar parallel stainless steel electrodes enclosed by quartz windows along the sides in order to confine the gas flow and provide optical access to the plasma volume. This forms a core plasma channel $30 \mathrm{~mm}$ in length and with a $1 \mathrm{~mm} \times 1 \mathrm{~mm}$ cross section. One electrode is grounded, and the other is driven at a frequency $\mathrm{f}=13.56$ $\mathrm{MHz}$, using a rf broadband amplifier via an impedance matching network. Typical rf-generator powers applied through the matching network are 5 to $70 \mathrm{~W}$, voltage amplitudes are several hundred $\mathrm{V}$, and total current amplitudes are in the range of 1-10 A. However, large stray capacitances within the matching network are expected due to the small dimensions of the active plasma region within the rf-APPJ, which considerably reduce the amount of rf-power actually coupled into the plasma. This assumption has been verified by recent electrical measurements using derivative probes by Lazovic et al., ${ }^{38}$ which show that the power consumed by the plasma is on the order of a few $\mathrm{W}$. This rf-APPJ produces 


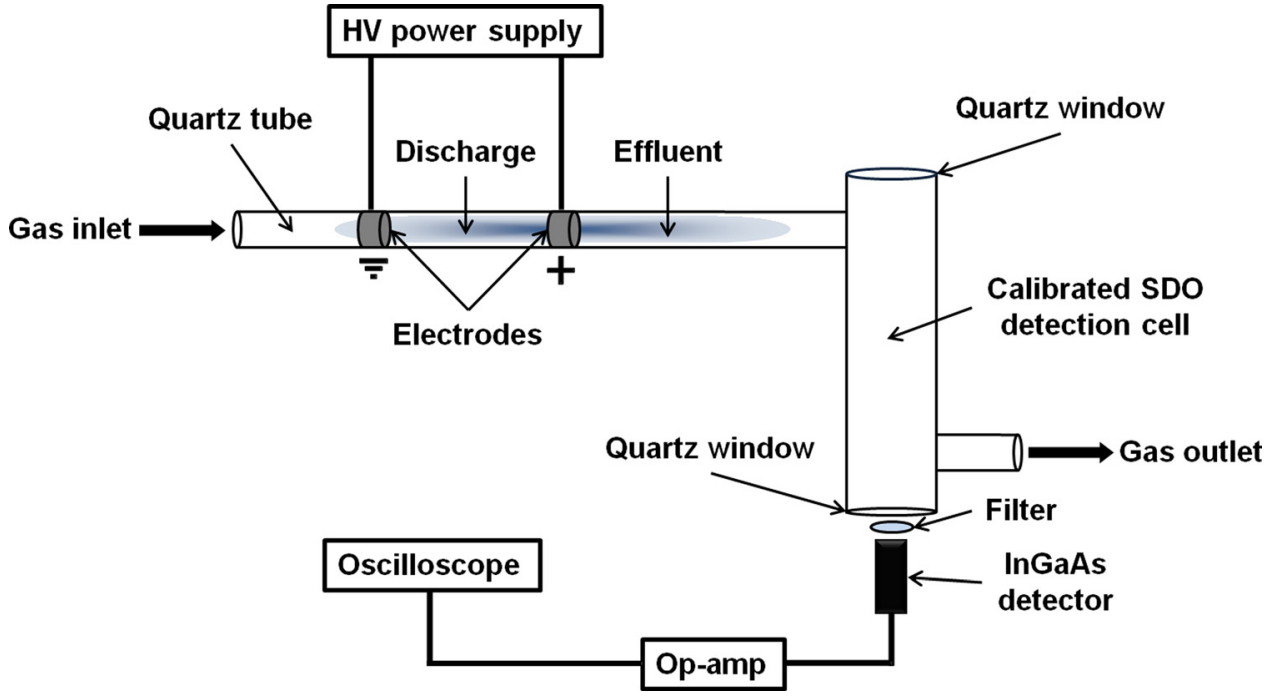

FIG. 2. (Color online) Schematic of the $\mathrm{kHz}$-driven atmospheric pressure plasma jet. a cold homogeneous $\alpha$-mode glow discharge at ambient pressure. The operational rf power range depends on the flow and feed gas composition. The mean electron energy is about $2 \mathrm{eV}$, and the electron density is up to $10^{17} \mathrm{~m}^{-3}$. 39 This APPJ device was developed by Schulz-von der Gathen et $a l^{40,41}$ and is based on the original concept of the APPJ introduced by Schütze et al., ${ }^{42}$ but scaled down and optimized for ideal optical access, providing a large optical solid angle. The downscaled dimensions maintain similar gas velocities in the range of some $10 \mathrm{~ms}^{-1}$, reducing the gas flow significantly to $\sim 1 \mathrm{slm}$. In this rf-driven APPJ, the electric field is perpendicular to the gas flow, and thus the effluent emitted from the plasma bulk into ambient air is charge-free, ${ }^{42}$ with its constituents dominated by radiation (from ultraviolet to infrared) and neutral species, including reactive neutrals. ${ }^{40,41,43}$

As shown in Fig. 2, the kHz-APPJ design investigated in this work is composed of a cylindrical capillary dielectric tube (quartz) with an inner diameter of $4 \mathrm{~mm}$ and an outer diameter of $6 \mathrm{~mm}$. Two external, $2 \mathrm{~mm}$ wide, tubular copper electrodes are assembled around the tube, forming a dielectric barrier discharge type configuration. The distance between electrodes can be varied. The electrode separation is typically a few centimeters. The downstream electrode is driven at a pulse excitation frequency of tens of $\mathrm{kHz}$ and a high voltage (1 to $10 \mathrm{kV}$ ) by using a high voltage pulse source (Haiden, PHF-2 K). A high-voltage probe (Tektronix P6015) and a calibrated Rogowski coil (Pearson 2877) connected to a digital oscilloscope (LeCroy WavePro 7300 A) have been used to measure the time dependent applied voltage and discharge current (see Fig. 3). This allows the determination of the power dissipated into the $\mathrm{kHz}$ plasma jet. The discharge current was measured as the difference between the total current, when the plasma is ignited, and the displacement current. The latter was obtained by measuring the circuit current when no plasma is present in the capillary tube. As we can see in Fig. 3, the majority of the discharge current is measured during the positive half of the applied voltage, while there is no significant discharge current outside the positive peak. In this $\mathrm{kHz}$-driven APPJ, the electric field is directed parallel to the gas flow. An intense plasma forms inside the glass tube between the two electrodes, and a relatively long pulsed plasma plume of few centimeters emerges at both sides of the powered electrode (downstream one) and propagates into the free space in the helium gas channel. The length of the plume has been found to depend on the operational parameters (e.g., applied voltage, gas flow rate). These plumes, although continuous to the naked eye, consist in fact of a transient series of plasma pulses when imaged on a nanosecond time scale. The plasma pulses have a velocity much greater than the gas flow velocity and are sustained through a streamer-like mechanism. $^{44,45}$

\section{B. Measurement of absolute singlet delta oxygen density}

Infrared emission at a wavelength of $1.27 \mu \mathrm{m}$ is one of the features of SDO presence, and it is commonly used for measuring SDO concentration. However, this emission is extremely weak because the transition is strictly forbidden

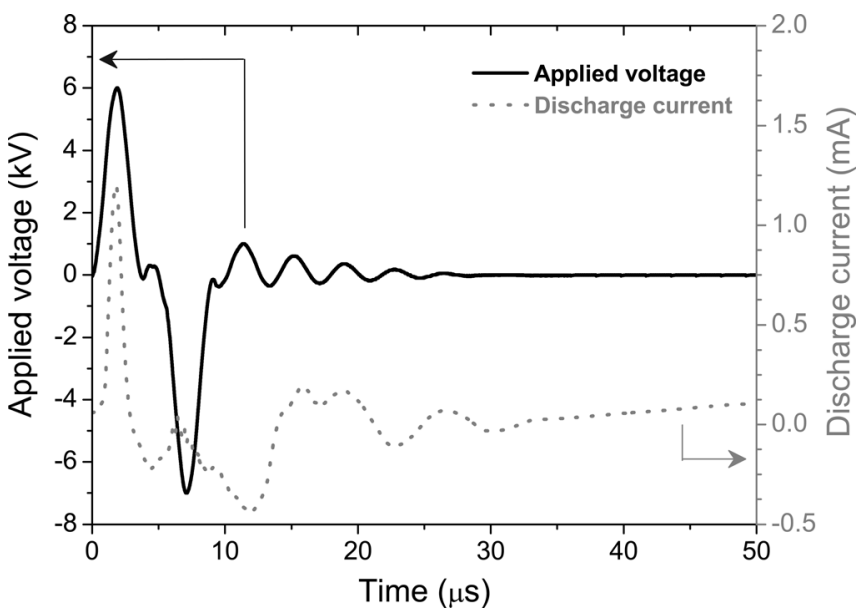

FIG. 3. Typical applied voltage and discharge current waveforms (during one cycle) of the kHz-driven dielectric barrier discharge with operation at 6 $\mathrm{kV}$ and at a $20 \mathrm{kHz}$ pulse repetition rate, with a helium flow of $2 \mathrm{slm}$. The inter-electrode distance is $25 \mathrm{~mm}$. 


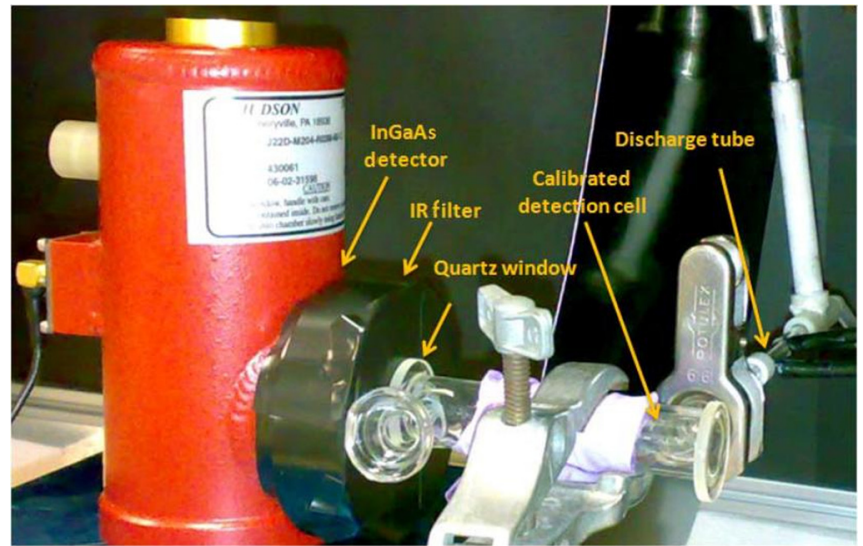

FIG. 4. (Color online) Experimental setup for measuring the absolute singlet delta oxygen density in the effluent of the kHz-APPJ. A similar setup was used for the rf-APPJ.

for electric dipole radiation, being permitted only for magnetic dipole radiation, with the Einstein coefficient on the order of $\sim 10^{-4} \mathrm{~s}^{-1}$, equivalent to a radiative lifetime of approximately $4500 \mathrm{~s}^{46}$ The determination of the absolute SDO number density by measuring the weak signal at 1.27 $\mu \mathrm{m}$ resulting from the radiative deexcitation of SDO is, thus, rather challenging, and the detection and calibration require considerable effort.

As illustrated in Fig. 4 for the case of the kHz-APPJ, the effluent gas lines of both APPJs are equipped with a calibrated detection cell allowing the measurement of the SDO density in the flowing effluent. This is done by monitoring the intensity of the radiative emission of SDO at $1.27 \mu \mathrm{m}$. The distance between the measurement cell and the rf-APPJ nozzle or the outer electrode of the $\mathrm{kHz}-\mathrm{APPJ}$ is approximately $10 \mathrm{~cm}$. The detection system consists of a calibrated liquid-nitrogen-cooled InGaAs detector (Judson model J22 D-M204-R03M-1.7) and a narrowband (19 nm bandpass) interference filter centered at $1.27 \mu \mathrm{m}$ (Andover 200FC39-25/ 1270). The signal of the InGaAs detector is amplified by an operational amplifier with a gain of $10^{7}$ and monitored with a digital oscilloscope (LeCroy WavePro 7300 A). Assuming that the spatial distribution of the SDO in the measurement cell is homogeneous, and knowing the sensitivity of the InGaAs detector $(0.9 \mathrm{~A} / \mathrm{W})$, the transmission curve of the interference filters $(35 \%$ transmission at $1.27 \mu \mathrm{m})$, the geometrical dimensions of the optical detection system, and the radiative transition probability of $\mathrm{SDO}\left(\mathrm{A}=2.256 \times 10^{-4}\right.$ $\left.\mathrm{s}^{-1}\right),{ }^{47}$ the SDO absolute density can be deduced from the amplitude of the InGaAs signal. In that procedure, a Monte Carlo simulation was used to evaluate the probability that a photon emitted in the detection cell will reach the $\mathrm{InGaAs}$ element of the detector. ${ }^{48}$ This figure was found to be $1.9 \times 10^{-4}$ in our geometry, in which the measurement cell is cylindrical ( $82 \mathrm{~mm}$ in length, $14 \mathrm{~mm}$ in diameter) with flat end faces of quartz (effective window diameter $=11 \mathrm{~mm}$ ), and the InGaAs detector has a $3 \mathrm{~mm}$ diameter circular surface and a $60^{\circ}$ collection angle. The distance from the cell window to the detector is fixed at $25 \mathrm{~mm}$. As a result, in our experimental setup, the SDO density is correlated to the in- tensity of the InGaAs signal by a factor of $3.77 \times 10^{15} \mathrm{SDO} /$ $\mathrm{cm}^{3}$ per $\mathrm{mV}^{49,50}$

\section{RESULTS AND DISCUSSION}

\section{A. Power variation}

Fig. 5(a) shows the evolution of the SDO density as a function of the applied power, measured in the effluent of the rf-APPJ, for two different $\mathrm{O}_{2}$ admixtures. We observe an over-linear increase of the SDO density of one order of magnitude. Whereas at low powers the rf-APPJ behaves like a typical $\alpha$-mode discharge, it changes to the $\gamma$-mode at higher powers. ${ }^{51}$ The discharge then becomes inhomogeneous and spatially constricted, with a significantly higher current density, showing bright concentrated discharge columns that can even become Ohmic, bearing the potential risk of electrode surface damage. For applied powers higher than those plotted in Fig. 5(a), it is not possible to sustain stable homogeneous glow discharges ( $\alpha$-mode). As can be seen in the figure, a larger $\mathrm{O}_{2}$ admixture shifts the operational range toward higher powers. This might be related to the energy consumption through molecular vibrational and rotational excitation, as well as dissociative processes not directly contributing to the plasma ionization. In Ref. 52, the production and destruction processes of the plasma species in the rf-APPJ are investigated in detail in numerical simulations benchmarked by phase-resolved optical emission spectroscopy and two-photon absorption laser-induced fluorescence spectroscopy for a specific gas mixture $\left(1 \mathrm{slm}\right.$ of $\mathrm{He}$ and $0.5 \%$ of $\left.\mathrm{O}_{2}\right)$. As found in Ref. 52, SDO is almost exclusively produced by the electronimpact excitation of $\mathrm{O}_{2}$, whereas its destruction is mainly driven by a two-body reaction with ozone. Thus, one can derive the following expression for the SDO density:

$$
n_{\mathrm{O}_{2}^{*}}=\frac{n_{e} n_{\mathrm{O}_{2}} k_{1}}{n_{\mathrm{O}_{3}} k_{2}} .
$$

Here, $n_{\mathrm{O}_{2}^{*}}, n_{e}$, and $n_{\mathrm{O}_{3}}$ denote the SDO, electron, and ozone density, respectively, and $\mathrm{k}_{1}$ and $\mathrm{k}_{2}$ are the rate coefficients of the corresponding reactions:

$$
\begin{gathered}
R_{1}: e+\mathrm{O}_{2} \rightarrow \mathrm{O}_{2}^{*}+e, \\
R_{2}: \mathrm{O}_{2}^{*}+\mathrm{O}_{3} \rightarrow 2 \mathrm{O}_{2}+\mathrm{O}^{*} .
\end{gathered}
$$

As such, an increase in the electron density, $\mathrm{O}_{2}$ density, or reduced electric field $(\mathrm{E} / \mathrm{N})$ favors $\mathrm{SDO}$ production. In contrast, an increase in the ozone density leads to a higher quenching of SDO. From Ref. 52, we also know that the electron density increases linearly with the applied power, whereas the E/N stays nearly constant. Thus, with increasing power, more SDO is expected to be produced. In addition, when the plasma volume is constant, increasing power means a higher power density. This leads to a higher gas temperature that ultimately causes the ozone density to decrease. These two effects of increasing power have already been experimentally verified. ${ }^{53}$ The dependence of ozone density on gas temperature is well known. With increasing gas temperature, the ozone production rate decreases and its destruction rate increases, both leading to a lower ozone 

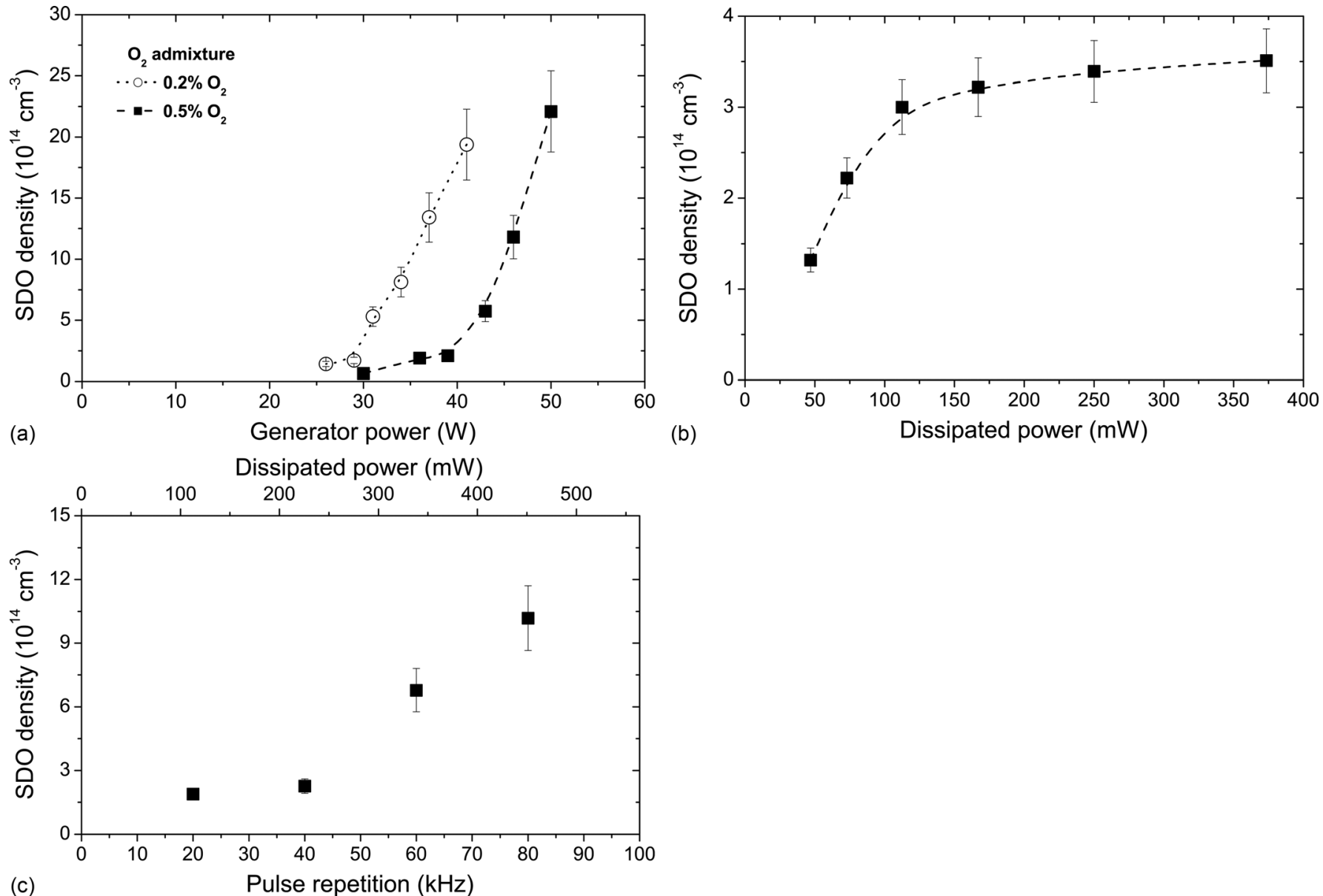

FIG. 5. (a) SDO density as a function of the applied $13.56 \mathrm{MHz}$ rf power with a helium flow of $1 \mathrm{slm}$ and different $\mathrm{O}_{2}$ admixtures. (b) SDO density as a function of the power dissipated into the $\mathrm{kHz}$ plasma jet when operated at different applied voltages $(5-8 \mathrm{kV})$ and at a $20 \mathrm{kHz}$ pulse repetition rate, with a helium flow of $2 \mathrm{slm}$ and an $\mathrm{O}_{2}$ admixture of $0.5 \%$. The inter-electrode distance is $25 \mathrm{~mm}$. (c) SDO density as a function of the pulse repetition rate while operating the $\mathrm{kHz}$ plasma jet at $6 \mathrm{kV}$, with a helium flow of $2 \mathrm{slm}$ and an $\mathrm{O}_{2}$ admixture of $0.5 \%$. The inter-electrode distance is $25 \mathrm{~mm}$. The corresponding dissipated power is marked on the top axis.

density. ${ }^{54,55}$ In conclusion, for a constant oxygen admixture, and from Eq. (1), it can be expected that the SDO density depends over-linearly on the applied power. It should be noted that only a small fraction of the generator power is actually coupled into the plasma, as there are losses in the connecting cables, matching network, and heating of the electrodes, as well as by rf-radiation of the jet device acting as an antenna. ${ }^{56}$ Even if we have not yet experimentally measured the power dissipated into the plasma, model calculations, ${ }^{52}$ in agreement with independent measurements, ${ }^{38}$ have allowed us to estimate it as being below $1 \mathrm{~W}$. The range of power coupled to the rf plasma is similar to the dissipated power that has been measured for the $\mathrm{kHz}$ device [see Fig. 5(b)].

Fig. 5(b) shows the evolution of the SDO density measured in the effluent of the $\mathrm{kHz}$-APPJ as a function of the dissipated power. As in the case of the rf-APPJ, we observe an increase of the SDO density. However, here the rise is less significant (by only approximately a factor of three), and it tends to saturate (there is a plateau region for dissipated powers higher than $250 \mathrm{~mW}$ ), in contrast to the continuous increase of the SDO density in the case of the rf-APPJ. It must be noted that the variation of the dissipated power is experimentally achieved by changing the applied voltage. The plateau region might, therefore, result from the observed increase of the ozone density with increasing applied voltage. ${ }^{53}$ Varying the applied voltage also causes the $\mathrm{E} / \mathrm{N}$ to change, which induces modifications in the plasma chemistry and, therefore, in the SDO density. Thus, a more defined way of studying the power dependence of the SDO density in the $\mathrm{kHz}$ device is to vary the pulse repetition.

Fig. 5(c) shows the evolution of the SDO density as a function of the pulse repetition rate, measured in the effluent of the $\mathrm{kHz}$-APPJ. While varying the pulse repetition rate, as the applied pulsed voltage stays constant, the $\mathrm{E} / \mathrm{N}$ remains the same. With increasing dissipated power, i.e., increasing pulse repetition, the time-averaged electron density also increases, which is likely to lead to a higher SDO production. Besides that, the gas temperature in the $\mathrm{kHz}$ plasma is expected to increase with the dissipated power, leading to a reduction of the ozone density. The SDO density dependence is, therefore, found here to be slightly over-linear, but not as strong as for the rf plasma. Nonetheless, we observe a strong increase of the SDO density of more than 5 times. 

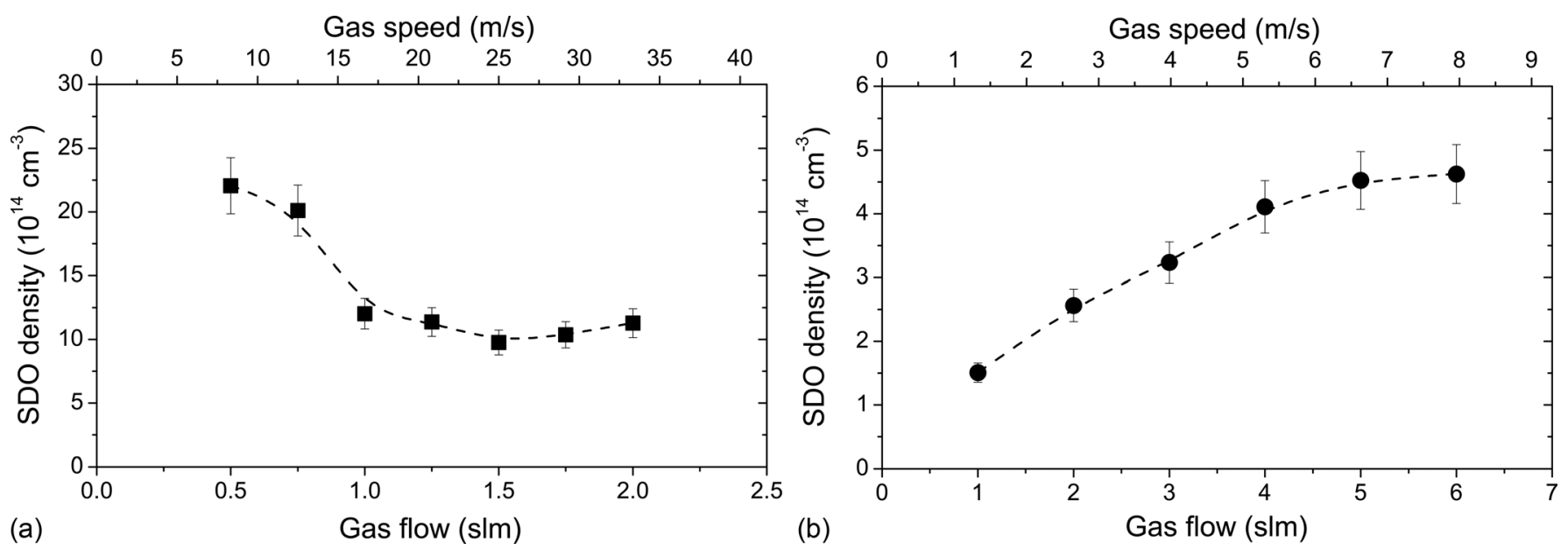

FIG. 6. (a) SDO density as a function of the gas flow while operating the rf plasma jet at $13.56 \mathrm{MHz}$, with an applied power of $46 \mathrm{~W}$ and an $\mathrm{O}_{2}$ admixture of $0.5 \%$. The corresponding gas speed is marked on the top axis. (b) SDO density as a function of the gas flow while operating the $\mathrm{kHz}$ plasma jet at $6 \mathrm{kV}$ and at $20 \mathrm{kHz}$, with an $\mathrm{O}_{2}$ admixture of $0.3 \%$. The inter-electrode distance is $25 \mathrm{~mm}$. The corresponding gas speed is marked on the top axis.

\section{B. Total gas flow variation}

Figs. 6(a) and 6(b) show the evolution of the SDO density as a function of the total gas flow, measured in the effluent of the rf and the $\mathrm{kHz}$ devices, respectively. The plotted curves show opposite trends. Whereas the SDO density (versus the gas flow) increases in the case of the kHz-APPJ, it decreases in the case of the rf-APPJ. The increase of the gas flow induces two competitive effects. First, a higher gas flow causes the transit time to the measurement cell to decrease and, even more important, shortens the residence time in the measurement cell. One should recall that the major SDO quencher is ozone, which is mainly produced in the effluent. In fact, from Ref. 43, we know that the ozone density grows with increasing distance to the rf-APPJ nozzle, due to the recombination of atomic oxygen with $\mathrm{O}_{2}$, until it saturates beyond a distance of few centimeters. As a result, shorter transport and residence times lead to less quenching of SDO molecules before their detection in the measurement cell. Second, higher gas flow usually causes the gas temperature to decrease, which normally induces higher ozone densities and, thus, more SDO destruction. The first effect explains the observed increase of the SDO density in the case of the $\mathrm{kHz}$ plasma [see Fig. 6(b)]. The reason behind the opposite trends observed in Figs. 6(a) and 6(b) might, then, be the different behavior of the gas temperature dependence on the gas flow in both jets. The gas temperature in the kHz-APPJ has been found to be quite close to room temperature $(305 \pm 15 \mathrm{~K}),{ }^{53}$ and lower than in the rf-APPJ $(335 \pm 15$ $\mathrm{K}){ }^{23} \mathrm{So}$, an increase of the gas flow cannot induce a considerable decrease of the gas temperature in the $\mathrm{kHz}$ plasma. Moreover, it has been experimentally observed that a higher gas flow induces a higher dissipated power in the $\mathrm{kHz}$ plasma, as well as an increase of the plasma volume, which could subsequently lead to increased SDO production. It must be noted that because the power density stays nearly constant, the gas temperature remains quite low. However, increasing the gas flow has a much greater effect on the gas temperature in the rf plasma. In fact, the operational range of the rf-APPJ, up to the transition from $\alpha$ - to $\gamma$-mode mentioned in the preceding section, has been found to shift to higher powers with increasing feed gas flow, indicating that a higher flow rate suppresses the thermal instability of the rf discharge to some extent. As decreasing gas temperature also leads to higher ozone densities and, therefore, greater SDO destruction, we can deduce from Fig. 6(a) that in the case of the rf-APPJ, the observed curve is loss-limited, as the positive effects of increasing the gas speed are overcome.

\section{C. $\mathrm{O}_{2}$ admixture variation}

Fig. 7(a) shows the evolution of the SDO density as a function of the $\mathrm{O}_{2}$ admixture, measured in the effluent of the rf-APPJ, for different applied powers. We generically observe a decrease of the SDO density with increasing $\mathrm{O}_{2}$ fraction. Recalling Eq. (1), and given that the $\mathrm{O}_{2}$ density increases with increasing $\mathrm{O}_{2}$ admixture, the curves plotted in Fig. 7(a) suggest that the ozone density increases over-linearly with the $\mathrm{O}_{2}$ admixture, as experimentally observed in Refs. 43 and 53. As such, the observed curves for the SDO density evolution seem to be loss-limited. However, varying the $\mathrm{O}_{2}$ fraction is also likely to change the electron density and the $\mathrm{E} / \mathrm{N}$, and the chemistry becomes even more complicated to analyze. It should be noted that our simulations of the rf-APPJ have so far been performed only for a fixed $\mathrm{O}_{2}$ admixture. ${ }^{52}$ So, a complete analysis of the modifications on the plasma chemistry induced by the variation of the $\mathrm{O}_{2}$ fraction is far beyond the scope of the present paper. When operating at $32 \mathrm{~W}$ of applied power, we observe the existence of an optimal value for the $\mathrm{O}_{2}$ admixture. In fact, the SDO density increases to around $0.1 \%$ of $\mathrm{O}_{2}$, and it decreases afterward. However, it was not always possible to determine the optimal values for the $\mathrm{O}_{2}$ percentage, as the rf discharge cannot be sustained in the stable homogeneous glow regime for high power and low $\mathrm{O}_{2}$ admixture due to the instabilities mentioned in Sec. III A.

Fig. 7(b) shows the evolution of the SDO density as a function of the $\mathrm{O}_{2}$ fraction, measured in the effluent of the $\mathrm{kHz}$ plasma, for different inter-electrode distances. Note that 

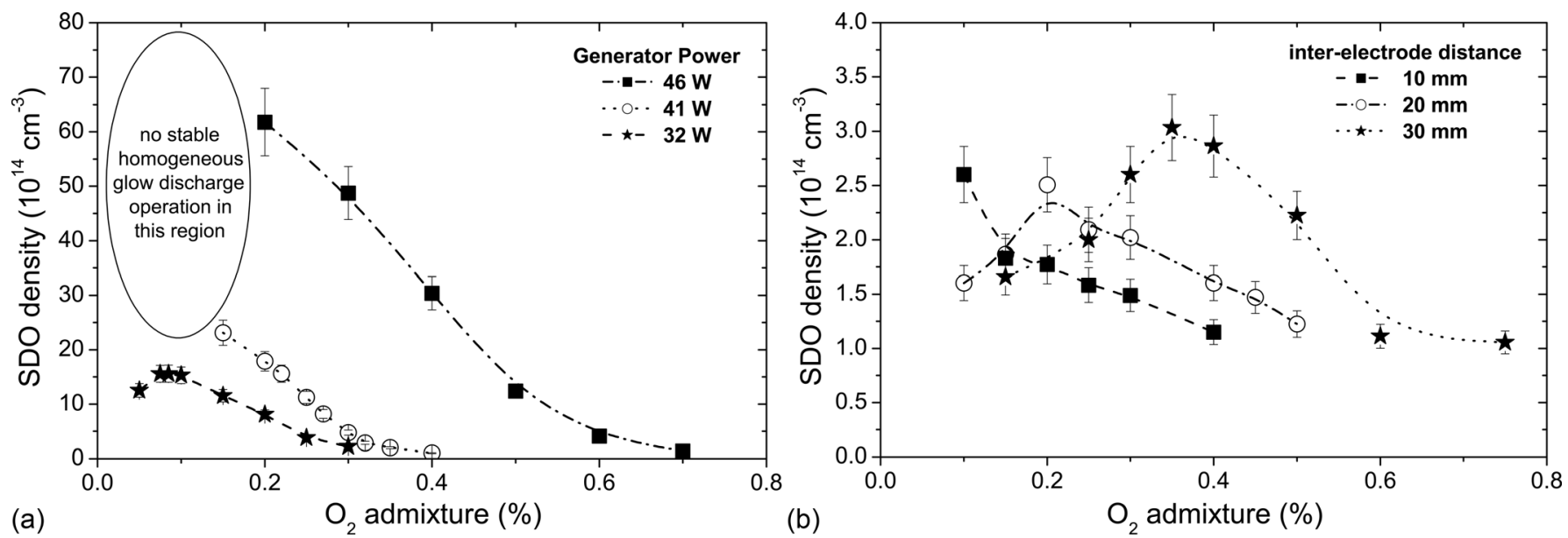

FIG. 7. (a) SDO density as a function of the oxygen admixture while operating the rf plasma jet at $13.56 \mathrm{MHz}$, with a He flow of 1 slm. (b) SDO density as a function of the oxygen fraction while operating the $\mathrm{kHz}$ plasma jet at $6 \mathrm{kV}$ and at $20 \mathrm{kHz}$, with a He flow of 2 slm.

for inter-electrode distances higher than $30 \mathrm{~mm}$, the plasma is not stable. Trends similar to those in Fig. 7(a) are observed. We can thus assume that, as in the case of the rfAPPJ, here the SDO density dependence on the $\mathrm{O}_{2}$ admixture also results from a competition between the $\mathrm{O}_{2}$ and ozone densities' variation with the $\mathrm{O}_{2}$ fraction. We also observe the existence of optimal values for the $\mathrm{O}_{2}$ admixture. However, the optimal values of $\mathrm{O}_{2}$ admixture seem to be higher in the $\mathrm{kHz}$ jet. Up to the maximum value of the SDO density, the plotted curves are production-limited, and after that point they become loss-limited. In Fig. 7(b), we also observe a shift of the maximum value toward a higher $\mathrm{O}_{2}$ admixture with increasing inter-electrode distance. In fact, the optimal value of the $\mathrm{O}_{2}$ percentage increases from less than $0.1 \%$ to almost $0.4 \%$ when the distance between electrodes is changed from 10 to $30 \mathrm{~mm}$. This might be related to the fact that at a constant applied voltage, the electric field decreases with increasing inter-electrode distance.

\section{CONCLUSIONS}

In this paper, we report absolute SDO density measurements in the effluent of two different APPJs. Despite the considerable differences between the two jets (excitation frequency, electric field direction, inter-electrode distance, plasma propagation), our results show that the SDO density dependences on the oxygen admixture and on the dissipated power are somewhat similar in the two APPJs. However, opposite trends have been observed for the gas flow dependence. Whereas the SDO density increases with gas flow in the $\mathrm{kHz}$ plasma, it decreases in the $\mathrm{rf}$ discharge. A maximum SDO density of $6.2 \times 10^{15} \mathrm{~cm}^{-3}$ was measured while operating the rf plasma at $46 \mathrm{~W}$ applied power with $1 \mathrm{slm}$ of $\mathrm{He}$ and an $\mathrm{O}_{2}$ admixture of $0.2 \%$. It should be pointed out that, for comparable operational conditions, SDO densities one order of magnitude higher have been consistently obtained with the rf-APPJ as compared to the $\mathrm{kHz}-\mathrm{APPJ}$. As discussed in this paper, the power dissipated into the two plasmas is similar $(<1 \mathrm{~W})$. However, given that the rf plasma volume is much smaller, the power density is much higher in this discharge as compared to the $\mathrm{kHz}$ plasma. As high yields of
SDO require a high specific energy deposition $\left(\sim 5-8 \mathrm{eV} / \mathrm{O}_{2}\right),{ }^{57}$ the rf-APPJ, having higher power densities, is likely to be more efficient in producing SDO. In addition, the gas temperature in the rf plasma has been found to be higher than that of the $\mathrm{kHz}$ discharge $(335 \pm 15 \mathrm{~K}$ versus $305 \pm 15$ $\mathrm{K}){ }^{23,53}$ This causes the ozone density to decrease, which induces a higher SDO density, because less SDO quenching by ozone occurs. The combination of these two effects may explain the much higher SDO densities found while operating the rf-APPJ. As shown in this paper, controlling the external operating conditions of each APPJ enables the tailoring of the SDO composition of both plasma effluents. This is an important achievement in the context of the potential biomedical applications of these plasma sources. As has been recently demonstrated, ${ }^{26}$ exposure to SDO-containing atmospheric plasma effluents can result in DNA damage.

\section{ACKNOWLEDGMENTS}

The authors thank V. Puech (LPGP, CNRS, and UPS11, Orsay, France) for providing the diagnostic setup for measuring the absolute singlet delta oxygen density. The authors acknowledge support from the UK Engineering and Physical Sciences Research Council (EPSRC) through a Science and Innovation Award (Grant No. EP/D06337X/1) and a Career Acceleration Fellowship (Grant No. EP/H003797/ 1). One of the authors (L.J.C.) is supported by the Northern Irish Department for Employment and Learning (DEL). Q.Th.A. acknowledges financial support from the Iraqi Ministry of Higher Education.

\footnotetext{
${ }^{1}$ M. Laroussi, Plasma Processes Polym. 2, 391 (2005).

${ }^{2}$ E. Stoffels, Contrib. Plasma Phys. 47, 40 (2007).

${ }^{3}$ G. Fridman, G. Friedman, A. Gutsol, A. B. Shekhter, V. N. Vasilets, and A. Fridman, Plasma Processes Polym. 5, 503 (2008).

${ }^{4}$ P. Rajasekaran, P. Mertmann, N. Bibinov, D. Wandke, W. Viol, and P. Awakowicz, J. Phys. D: Appl. Phys. 42, 225201 (2009).

${ }^{5}$ M. G. Kong, G. Kroesen, G. Morfill, T. Nosenko, T. Shimizu, J. van Dijk, and J. L. Zimmermann, New J. Phys. 11, 115012 (2009).

${ }^{6} \mathrm{M}$. Laroussi, IEEE Trans. Plasma Sci. 37, 714 (2009).

${ }^{7}$ G. E. Morfill, M. G. Kong, and J. L. Zimmermann, New J. Phys. 11, 115011 (2009).
} 
${ }^{8}$ C. Jiang, M. T. Chen, C. Schaudinn, A. Gorur, P. T. Vernier, J. W. Costerton, D. E. Jaramillo, P. P. Sedghizadeh, and M. A. Gundersen, IEEE Trans. Plasma Sci. 37, 1190 (2009).

${ }^{9}$ M. Vandamme, E. Robert, S. Pesnel, E. Barbosa, S. Dozias, J. Sobilo, S. Lerondel, A. Le Pape, and J. M. Pouvesle, Plasma Processes Polym. 7, 264 (2010).

${ }^{10}$ B. Lacour, V. Puech, and S. Pasquiers, Recent Res. Dev. Appl. Phys. 6, 149 (2003).

${ }^{11}$ U. Kogelschatz, Pure Appl. Chem. 62, 1667 (1990).

${ }^{12}$ C. M. O. Mahony, T. Gans, W. G. Graham, P. D. Maguire, and Z. Lj. Petrovic, Appl. Phys. Lett. 93, 011501 (2008).

${ }^{13}$ H. Koinuma, H. Ohkubo, T. Hashimoto, K. Inomata, T. Shiraishi, A. Miyanaga, and S. Hayashi, Appl. Phys. Lett. 60, 816 (1992).

${ }^{14}$ M. Teschke, J. Kedzierski, E. G. Finantu-Dinu, D. Korzec, and J. Engemann, IEEE Trans. Plasma Sci. 33, 310 (2005).

${ }^{15}$ S. Forster, C. Mohr, and W. Viol, Surf. Coat. Technol. 200, 827 (2005).

${ }^{16}$ J. Zhang, J. Sun, D. Wang, and X. Wang, Thin Solid Films 506, 404 (2006).

${ }^{17}$ J. L. Walsh, J. J. Shi, and M. G. Kong, Appl. Phys. Lett. 88, 171501 (2006).

${ }^{18}$ C. Cheng, L. Peng, X. Lei, Z. Li-Ye, Z. Ru-Juan, and Z. Wen-Rui, Chin. Phys. 15, 1544 (2006).

${ }^{19}$ D. B. Kim, J. K. Rhee, S. Y. Moon, and W. Choe, Appl. Phys. Lett. 89, 061502 (2006).

${ }^{20}$ Y. C. Hong and H. S. Uhm, Appl. Phys. Lett. 89, 221504 (2006).

${ }^{21}$ J. Waskoenig and T. Gans, Appl. Phys. Lett. 96, 181501 (2010).

${ }^{22}$ K. Niemi, S. Reuter, L. M. Graham, J. Waskoenig, and T. Gans, Appl. Phys. Lett. 95, 151504 (2009).

${ }^{23}$ K. Niemi, S. Reuter, L. M. Graham, J. Waskoenig, N. Knake, V. Schulzvon der Gathen, and T. Gans, J. Phys. D: Appl. Phys. 43, 124006 (2010).

${ }^{24}$ E. Stoffels, I. E. Kieft, R. E. J. Sladek, L. J. M. van den Bedem, E. P. van der Laan, and M. Steinbuch, Plasma Sources Sci. Technol. 15, S169 (2006).

${ }^{25}$ K. H. Becker, A. Koutsospyros, S. M. Yin, C. Christodoulatos, N. Abramzon, J. C. Joaquin, and G. Brelles-Marino, Plasma Phys. Controlled Fusion 47, B513 (2005).

${ }^{26}$ J. S. Sousa, G. Bauville, B. Lacour, V. Puech, M. Touzeau, and J. L. Ravanat, Appl. Phys. Lett. 97, 141502 (2010).

${ }^{27}$ D. O'Connell, L. J. Cox, W. B. Hyland, S. J. McMahon, S. Reuter, W. G. Graham, T. Gans, and F. J Currell, Appl. Phys. Lett. 98, 043701 (2011).

${ }^{28}$ N. I. Krinsky, in Singlet Oxygen, edited by H. H. Wasserman and R. W. Murray (Academic, New York, 1979).

${ }^{29}$ Singlet Oxygen, edited by A. A. Frimer (CRC, Boca Raton, FL, 1985).

${ }^{30}$ Methods in Enzymology, Singlet Oxygen, UV A and Ozone, edited by L. Packer and H. Sies (Academic, New York, 2000).

${ }^{31}$ C. S. Foote, Photochem. Photobiol. 54, 659 (1991).

${ }^{32}$ H. Tatsuzawa, T. Maruyama, N. Misawa, K. Fujimori, K. Hori, Y. Sano, Y. Kambayashi, and M. Nakano, FEBS Lett. 439, 329 (1998).
${ }^{33}$ J. L. Ravanat, G. R. Martinez, M. G. H. Medeiros, P. di Mascio, and J. Cadet, Tetrahedron 62, 10709 (2006).

${ }^{34}$ K. R. Weishaupt, C. J. Gomer, and T. J. Dougherty, Cancer Res. 36, 2326 (1976).

${ }^{35}$ T. J. Dougherty, C. J. Gomer, B. W. Henderson, G. Jori, D. Kessel, M. Korbelik, J. Moan, and Q. Peng, J. Natl. Cancer Inst. 90, 889 (1998).

${ }^{36}$ F. Stewart, P. Baas, and W. Star, Radiother. Oncol. 48, 233 (1998).

${ }^{37}$ C. Schweitzer and R. Schmidt, Chem. Rev. 103, 1685 (2003).

${ }^{38}$ S. Lazovic, D. Maletic, N. Puac, G. Malovic, A. Dordevic, and Z. L. Petrovic, in Proceedings of the 20th ESCAMPIG, Novi Sad, Serbia, 13-17 July 2010, p. 2.29.

${ }^{39}$ J. Park, I. Henins, H. W. Herrmann, G. S. Selwyn, and R. F Hicks., J. Appl. Phys. 89, 20 (2001).

${ }^{40}$ V. Schulz-von der Gathen, V. Buck, T. Gans, N. Knake, K. Niemi, S. Reuter, L. Schaper, and J. Winter, Contrib. Plasma Phys. 47, 510 (2007).

${ }^{41}$ V. Schulz-von der Gathen, L. Schaper, N. Knake, S. Reuter, K. Niemi, T. Gans, and J. Winter, J. Phys. D: Appl. Phys. 41, 194004 (2008).

${ }^{42}$ A. Schütze, J. Y. Jeong, S. E. Babayan, J. Park, G. S. Selwyn, and R. F. Hicks, IEEE Trans. Plasma Sci. 26, 1685 (1998).

${ }^{43}$ D. Ellerweg, J. Benedikt, A. von Keudell, N. Knake, and V. Schulz-von der Gathen, New J. Phys. 12, 013021 (2010).

${ }^{44}$ B. L. Sands, B. N. Ganguly, and K. Tachibana, Appl. Phys. Lett. 92, 151503 (2008).

${ }^{45}$ D. O'Connell, in Proceedings of the 63rd Gaseous Electronics Conference, Paris, France, 4-8 October 2010

${ }^{46}$ A. A. Ionin, I. V. Kochetov, A. P. Napartovich, and N. N. Yuryshev, J. Phys. D: Appl. Phys. 40, R25 (2007).

${ }^{47}$ S. M. Newman, A. J. Orr-Ewing, D. A. Newnham, and J. J. Ballard, J. Phys. Chem. A 104, 9467 (2000).

${ }^{48}$ G. J. M. Hagelaar and L. C. Pitchford, private communication (2006).

${ }^{49}$ J. S. Sousa, G. Bauville, B. Lacour, V. Puech, M. Touzeau, and L. C. Pitchford, Appl. Phys. Lett. 93, 011502 (2008).

${ }^{50}$ J. S. Sousa, G. Bauville, B. Lacour, V. Puech, and M. Touzeau, Eur. Phys. J. Appl. Phys. 47, 22807 (2009).

${ }^{51}$ X. Yang, M. Moravej, G. R. Nowling, S. E. Babayan, J. Panelon, J. P. Chang, and R. F. Hicks, Plasma Sources Sci. Technol. 14, 314 (2005).

${ }^{52}$ J. Waskoenig, K. Niemi, N. Knake, L. M. Graham, S. Reuter, V. Schulz-von der Gathen, and T. Gans, Plasma Sources Sci. Technol. 19, 045018 (2010).

${ }^{53}$ J. S. Sousa, V. Puech, Q. Algwari, L. J. Cox, K. Niemi, T. Gans, and D. O'Connell, in Proceedings of the 63rd Gaseous Electronics Conference, Paris, France, 4-8 October 2010.

${ }^{54}$ B. Eliasson, M. Hirth, and U. Kogelschatz, J. Phys. D: Appl. Phys. 20, 1421 (1987)

${ }^{55}$ J. Chen and J. H. Davidson, Plasma Chem. Plasma Process. 22, 495 (2002).

${ }^{56}$ V. J. Law, S. Daniels, J. L. Walsh, M. G. Kong, L. M. Graham, and T. Gans, Plasma Sources Sci. Technol. 19, 034008 (2010).

${ }^{57}$ D. S. Stafford and M. J. Kushner, J. Appl. Phys. 96, 2451 (2004). 